Proceedings

\title{
Isolation of indigenous yeasts from unripened grapes not subjected to antifungal treatments ${ }^{\dagger}$
}

\author{
José Juan Mateo, Patricia Garcerà and Sergi Maicas *(i) \\ Departament de Microbiologia i Ecologia. Universitat de València, 46100, Burjassot. Spain \\ * Correspondence: sergi.maicas@uv.es; Tel.: (+34-963543214) (S.M.) \\ + Presented at the 1st International Electronic Conference on Microbiology, \\ 02-30 November 2020; Available online: https:/ / https:/ / ecm2020.sciforum.net/
}

Published: Day Month 2020

\begin{abstract}
The wine fermentation process is very complex and involves different types of yeasts. While the predominant one is Saccharomyces cerevisiae, it has long been known that other non-Saccharomyces yeasts also play an important role. Their action is mainly known in the early stages of fermentation. However, one should not overlook the processes and changes that non-Saccharomyces yeast populations may have undergone during previous stages of grape berry ripening. The whole process is conditioned by several environmental factors as well as the possibility that they have been subjected to some antifungal treatment. In our study we controlled the dynamics of non- Saccharomyces yeast populations during the ripening process, using PCR and enzymatic analysis. Some yeasts not usually found in wine fermentation (Aureobasidium pullulans, Cryptococcus sp., Metschnikowia pulcherrima and Rodotorula mucilaginosa) have been identified. These yeasts could be affected by antifungal treatments used in wineries, and this fact could explain the novelty of their isolation and identification. After their extensive characterization, these yeasts can be used to implement new biotechnological processes.
\end{abstract}

Keywords: yeast; non-Saccharomyces; grape berry; population dynamics; ripening; wine

\section{Introduction}

Grape microbiota refers to all species of filamentous fungus, yeast and bacteria that have been found in grape berries, in vineyard soil or in wines [1]. Yeasts that are found in grape berries can be classified into two groups: (i) Saccharomyces, those which are responsible for sugar fermentation in grape berries, and (ii) non-Saccharomyces or wild yeast that can participate in the beginning of the fermentation process [2]. The non-Saccharomyces species present in the grape juice and, in the first stages of fermentation, are divided into three groups: yeasts that are mostly aerobic (Pichia spp., Rhodotorula spp., or Cryptococcus albidus), yeasts with low fermentation ability (Kloeckera apiculata, K. apis and K. javanica) and yeasts that display fermentative metabolism (Metschnikowia pulcherrima, Kluyveromyces marxiamus and Zygosaccharomyces bailii) [3]. Nevertheless, non-Saccharomyces yeasts can also be detected before the fermentation process, i.e., during ripening and harvest processes. The importance of these yeasts is their contribution to different wine features, flavor and bouquet principally which is dependent on metabolites concentration. Initially it was believed that all non-Saccharomyces species died after the beginning of alcoholic fermentation but further studies do not support this statement [4]. Yeasts influence beverage aroma by different mechanisms; of these, de novo biosynthesis of aroma compounds is probably the most important [5]. The variety of odor compounds produced by non-Saccharomyces yeasts is already known. The contribution of non-Saccharomyces yeasts to flavor quality can take various forms. Production of glycerol by Candida 
stellata and esters by C. pulcherrima has been reported [6]. Other non-Saccharomyces yeasts are also widely recognized for producing glucosidase enzymes, which, by hydrolyzing such bonds, can release volatile compounds linked to sugars, giving greater complexity to the aromatic profile [7]. Furthermore, metabolic interactions have been noticed between $S$. cerevisiae and non-Saccharomyces wine species during the fermentation process. There are evidences that the interaction between some yeast species, when they develop together during fermentation, produces hardly predictable metabolites, which could alter the wine composition in chemical and aromatic ways [8]. In addition, these synergic metabolic interactions between different yeast species could be used to conceive new technology in the fermentation field [9].

Viticulture represents an important agricultural practice in many countries and the long-term use of organic and inorganic pesticides in vineyards has resulted in increased concentrations of these pollutants in soils and other environmental compartments [10]. Vineyard soils are usually highly degraded soils in terms of biochemical properties and are thus more susceptible to contamination. Nevertheless, few studies have been developed regarding the impact of these products on the yeast population diversity [11].

The aim of this work was to isolate, identify and characterize non-Saccharomyces yeasts along the grape ripening process in vineyards untreated with antifungal products, different microorganisms detected.

\section{Results}

\subsection{Groups and Population Dynamics}

Seven groups of yeasts were proposed attending to their morphology, and then the number of each group of yeasts on the grape surface was obtained. The numbers raised from $3.33 \times 10^{1} \mathrm{cfu} / \mathrm{mL}$ of a single species at the beginning to $1.67 \times 10^{3} \mathrm{cfu} / \mathrm{mL}$ at the end of the ripening process (Table 1 ).

Table 1. Count of different yeast populations ( $\mathrm{cfu} / \mathrm{mL})$.

\begin{tabular}{cccccc}
\hline \multirow{2}{*}{ Group } & \multicolumn{5}{c}{ Time (days) } \\
\cline { 2 - 6 } & $\mathbf{0}$ & $\mathbf{1 4}$ & $\mathbf{2 3}$ & $\mathbf{3 1}$ & $\mathbf{3 8}$ \\
\hline $\mathbf{1}$ & $3.33 \times 10^{1}(10.6)^{*}$ & $3.67 \times 10^{1}(15.4)$ & $3.33 \times 10^{1}(14.3)$ & $1.66 \times 10^{2}(10.5)$ & $3.80 \times 10^{1}(11.6)$ \\
$\mathbf{2}$ & nd & $4.66 \times 10^{2}(12.8)$ & $2.30 \times 10^{2}(16.8)$ & $9.66 \times 10^{2}(13.6)$ & $6.66 \times 10^{1}(16.2)$ \\
$\mathbf{3}$ & nd & $1.00 \times 10^{2}(9.6)$ & nd & nd & $3.00 \times 10^{1}(14.9)$ \\
$\mathbf{4}$ & nd & $6.67 \times 10^{0}(11.2)$ & nd & nd & nd \\
$\mathbf{5}$ & nd & nd & $2.33 \times 10^{1}(13.2)$ & nd & nd \\
$\mathbf{6}$ & nd & nd & $2.33 \times 10^{1}(10.7)$ & $3.33 \times 10^{1}(10.5)$ & nd \\
$\mathbf{7}$ & nd & nd & nd & nd & $1.54 \times 10^{3}(9.8)$ \\
\hline Total & $3.33 \times 10^{1}$ & $5.19 \times 10^{2}$ & $3.10 \times 10^{2}$ & $1.17 \times 10^{3}$ & $1.67 \times 10^{3}$ \\
\hline \multicolumn{7}{c}{$*$ Values in brackets represent standard deviation $(\mathrm{n}=3)}$. \\
\end{tabular}

After the incubation period, seven different morphological groups of yeasts were observed on MA plates. At the beginning of the study (day 0 ), $100 \%$ of the grown colonies belong to the morphological group 1, but after two weeks (14th day) morphological types 2, 3 and 4 appear, becoming the fourth the main (89.78\%). After 23 days since the beginning of the study, the second morphological group is still the prevailing $(74.19 \%)$, but two new morphological groups have shown up, 5 and 6 , and 3 and 4 do not grow anymore. At the 31st day, the second morphological group is still being the main ( $82.56 \%)$ and the morphological group 5 does not grow. At the end of the study (38th day) there is a new morphological group, the 7 , which is predominant $(72.64 \%)$ at the end of the study. 


\subsection{Molecular Identification}

For molecular characterization, the PCR product of the ITS of 31 isolates was examined by electrophoresis. RFLP of these amplicons produced a characteristic band profile for each strain (Table 2). Subsequently, genomic DNA of all isolates were subjected to PCR amplification of the D1/D2 region and were identified by comparing sequences using the NCBI blast program (Table 2).

Table 2. PCR lenght and match with database sequences for identification

\begin{tabular}{cclc}
\hline Group & PCR $^{a}$ & Closest Relative Species & Matching Nucleotide (\%) $^{b}$ \\
\hline 1 & 630 & Metschnikowia pulcherrima & 99.5 \\
2 & 500 & Aureobasidium pullulans & 99.8 \\
3 & 600 & Crytococcus uzbekistanensis & 99.5 \\
4 & 740 & Rhodotorula mucilaginosa & 99.9 \\
5 & 700 & Crytococcus adeliensis & 99.5 \\
6 & 600 & Crytococcus sp.CF-285748 & 99.7 \\
7 & 630 & Quambalaria cyanescens & 99.5 \\
\hline
\end{tabular}

$a$ PCR amplified rDNA size. ${ }^{b}$ Sequence identity in the D1/D2 region of isolates of the 26S ribosomal gene and closest relative species in the NCBI GenBank database.

\subsection{Enzymatic Activities}

The results of the tests conducted in culture mediums for qualitative detection of the different enzymatic activities are shown in Table 3 where it is observed that the great majority of the identified species present $\beta$-glucosidase and protease activities are detected in almost all the yeasts studied, while only isolates from Quambalaria cyanescens present lipase activity. Furthermore, no microorganism presents xylanase nor pectinase activity. These results do not agree with those published by Esteve-Zarzoso et al. [12] but are consistent with experimental data reported by Charoenchai et al. [13].

Table 3. Enzymatic characterization of the isolates.

\begin{tabular}{lccccc}
\hline \multirow{2}{*}{ Microorganism } & \multicolumn{5}{c}{ Enzymatic Activities } \\
\cline { 2 - 6 } & $\beta$-glucosidase & Protease & Lipase & Xylanase & Pectinase \\
\hline Crytococcus adeliensis & + & + & - & - & - \\
Cryptococcus sp. CF-285748 & + & + & - & - & - \\
Metschnikowia pulcherrima & + & + & - & - & - \\
Aureobasidium pullulans & + & + & - & - & - \\
Cryptococcus uzbekistanensis & - & + & - & - & - \\
Rhodotorula mucilaginosa & + & + & - & - & - \\
Quambalaria cyanescens & + & + & + & - & - \\
\hline
\end{tabular}

\section{Discussion}

Some qualitative and quantitative differences can be observed between these results and those obtained in the same vineyard in previous years [7]. In samples from untreated vineyards, yeast population increased during the ripening process, being at its maximum in the final stage. At the beginning of this process, the predominant species is M. pulcherrima. However, while the ripening process progresses, the population of this specie decreases, being replaced by A. pullulans, C. uzbekistanensis and R. mucilaginosa, although the numbers of these yeasts are lower than M. pulcherrima population at the beginning of the process. These species are also replaced, with M. pulcherrima being the only one that presents during all of the ripening process. Thereby, in the middle of the process, the species $C$. adeliensis and Cryptococcus 
sp. CF-285748 appear. Although Cryptococcus genus is mentioned as one of the typical one pertaining to non-Saccharomyces yeasts and, therefore, present in the surface of grapes [14], these two species are not typical ones, but both have been isolated in other studies $[15,16]$. There are not many references regarding the isolation and characterization of Cryptococcus sp. CF-285748; however, C. adeliensis is described by Scorzetti et al. [17] as a species from the Cryptococcus genus. Finally, in the last phase of ripening, a new species appears, Quambalaria cyanescens, of which the population number is well above the rest of isolated microorganisms. This microorganism has been found in a wide range of ecological niches, being symbiont in species of Corymbia and Eucalyptus [18]. Hence, although this last species is well described [18], there are not studies regarding its presence in the must nor in the grape surface. The fact that this yeast only appears at the end of the ripening process may be due to the application of antifungal treatments during most parts of the period in which the samples were collected. [11,19]. Some of the microorganisms described in this work are not the common type of yeast founded on grape surface. This fact may be caused by several factors. First, there is a limited number of works studying the yeast-like microbiota present during the ripening of grapes and its dynamics during this process [20]. On the other hand, the origin of the grapes should be considered, which could explain one part of the dissimilarity in terms of diversity of non-Saccharomyces yeasts isolated in the different studies. Regarding the population dynamics, A. pullulans is one of the main yeasts isolated in unripe grapes, although its population decreases along the ripening process, being undetectable when grapes are harvested [21]. This result agrees with our data, as A. pullulans appears at the beginning of the ripening process, but it has not been isolated in the later phases of the process. It is also reported the presence of R. mucilaginosa and Cryptococcus sp. during the midpoint of the ripening process, although the abundance of $R$. mucilaginosa in our study is smaller than the one observed in other studies [21].

The glycoside flavor potential remains rather constant during fermentation and in drinks as well. This fact opened a new field of rigorous investigation on the chemistry of glycoconjugated flavor compounds to exploit this significant flavor source [22]. The sensorial features of the wines produced with Muscat grapes are connected to the level of terpene alcohols, so an improvement of such a level, as a result of hydrolytic processes conducted by non-Saccharomyces yeasts is expected. Isolates from Hanseniaspora uvarum and $H$. vineae have been proved to be candidates to be used in vinification procedures to improve wine olfactive properties [23].

\section{Materials and Methods}

\subsection{Samples}

Samples were collected in a winery without antifungal treatments located in Iniesta, Cuenca, Spain $\left(39^{\circ} 26^{\prime} \mathrm{N}, 1^{\circ} 48^{\prime} \mathrm{W}\right)$ between 25 July and 1 September (2017). The samples were taken in different stages of the ripening process and were stored in sterile bags, keeping them at $-20{ }^{\circ} \mathrm{C}$ until its analysis.

\subsection{Yeasts Isolation}

Samples were homogenized by using a mortar and then left for $24 \mathrm{~h}$ at $4{ }^{\circ} \mathrm{C}$. Decimal dilutions were made in saline solution, and $100 \mu \mathrm{L}$ for each dilution were inoculated in Malt Agar plates (MA) as described in [24]. A total of 105 colonies were selected and cultured in MA to obtain pure cultures. The colonies that grew were observed under the optic microscope in order to establish their cellular morphology.

\subsection{Molecular Identification Using rDNA Sequence}

Yeast strain was revealed by PCR amplification for the D1/D2 domain of 26S rDNA of sample strains using the primers NL1 and NL4 [25]. Direct sequencing of the purified PCR products was performed 
by ABI Prism BigDye Terminator Cycle Sequence Ready Reaction Kit (Applied Biosystems, Stafford, TX, USA). The sequences were aligned, by using the BLAST program as described by Wirth et al. [25].

\subsection{Enzymatic Characterization}

Enzymatic characterization for protease, $\beta$-glucosidase, pectinase, xylanase and lipase activities) were performed basically as described in [24].

\section{Conclusions}

Usually described non-Saccharomyces yeasts are an interesting source of enzymes to be used in wine-making. Isolation of non-usual yeasts in the surface of unripened grapes opens a new door to obtain new enzymes with new potential to be used in biotechnological processes. Further studies should be developed to characterize these "new" enzymes and determine their potential use in enology.

Author Contributions: Conceptualization and writing, S.M. and J.J.M.; investigation, P.G. All authors have read and agreed to the published version of the manuscript.

\section{Abbreviations}

The following abbreviations are used in this manuscript:

PCR Polymerase Chain Reaction

MA Mal Agar

ITS Internal Transcribed Spacers

rDNA ribosomal DNA

\section{References}

1. Arévalo Villena, M.; Úbeda Iranzo, J.; Cordero Otero, R.; Briones Pérez, A. Optimization of a rapid method for studying the cellular location of beta-glucosidase activity in wine yeasts. J. Appl. Microbiol. 2005, 99, 558-564, doi:10.1111/j.1365-2672.2005.02627.x.

2. Jolly, N.; Varela, C.; Pretorius, I. Not your ordinary yeast: Non-Saccharomyces yeasts in wine production uncovered. FEMS Yeast Res. 2014, 14, 215-237, doi:10.1111/1567-1364.12111.

3. Combina, M.; Mercado, L.; Borgo, P.; Elia, A.; Jofré, V.; Ganga, A.; Martinez, C.; Catania, C. Yeasts associated to Malbec grape berries from Mendoza, Argentina. J. Appl. Microbiol. 2005, 98, 1055-1061, doi:10.1111/j.1365-2672.2005.02540.x.

4. Fleet, G.H. Yeast interactions and wine flavour. Int. J. Food Microbiol. 2003, 86, 11-22, doi:10.1016/S0168-1605(03)00245-9.

5. Styger, G.; Jacobson, D.; Bauer, F. Identifying genes that impact on aroma profiles produced by Saccharomyces cerevisiae and the production of higher alcohols. Appl. Microbiol. Biotechnol. 2011, 91, 713-730, doi:10.1007/s00253-011-3237-z.

6. Jolly, N.; Augustyn, O.; Pretorius, I. The use of Candida pulcherrima in combination with Saccharomyces cerevisiae for the production of Chenin blanc wine. S. Afr. J. Enology Vitic. 2003, 24, 63-69, doi:doi.org/10.21548/24-2-2641.

7. Mateo, J.; Peris, L.; Ibañez, C.; Maicas, S. Characterization of glycolytic activities from non-Saccharomyces yeasts isolated from Bobal musts. J. Ind. Microbiol. Biotechnol. 2011, 38, 347-354, doi:10.1007/s10295-010-0780-z.

8. Anfang, N.; Brajkovich, M.; Goddard, M. Co-fermentation with Pichia kluyveri increases varietal thiol concentrations in sauvignon blanc. Aust. J. Grape Wine Res. 2009, 15, 1-8, doi:10.1111/j.1755-0238.2008.00031.x.

9. Ciani, M.; Comitini, F.; Mannazzu, I.; Domizio, P. Controlled mixed culture fermentation: A new perspective on the use of non-Saccharomyces yeasts in winemaking. FEMS Yeast Res. 2010, 10, 123-133, doi:10.1111/j.1567-1364.2009.00579.x. 
10. Hildebrandt, A.; Guillamón, M.; Lacorte, S.; Tauler, R.; Barceló, D. Impact of pesticides used in agriculture and vineyards to surface and groundwater quality (North Spain). Water Res. 2008, 42, 3315-3326, doi:10.1016/j.watres.2008.04.009.

11. Milanović, V.; Comitini, F.; Ciani, M. Grape berry yeast communities: Influence of fungicide treatments. Int. J. Food Microbiol. 2013, 161, 240-246, doi:10.1016/j.ijfoodmicro.2012.12.019.

12. Esteve-Zarzoso, B., M.P.R.D.; Querol, A. The role of non-Saccharomyces yeasts in industrial winemaking. Int. Microbiol. 1998, 1, 143-148.

13. Charoenchai, C.; Fleet, G.H.; Henschke, P.A.; Todd, B.E.N.T. Screening of non-Saccharomyces wine yeasts for the presence of extracellular hydrolytic enzymes. Aust. J. Grape Wine Res. 1997, 3, 2-8, doi:10.1111/j.1755-0238.1997.tb00109.x.

14. Sáenz-Navajas, M.P.; Avizcuri, J.M.; Ballester, J.; Fernández-Zurbano, P.; Ferreira, V.; Peyron, D.; Valentin, D. Sensory-active compounds influencing wine experts' and consumers' perception of red wine intrinsic quality. LWT Food Sci. Technol. 2015, 60, 400-411, doi:10.1016/j.lwt.2014.09.026.

15. Barata, A.; Malfeito-Ferreira, M.; Loureiro, V. The microbial ecology of wine grape berries. Int. J. Food Microbiol. 2012, 153, 243-259, doi:10.1016/j.ijfoodmicro.2011.11.025.

16. Hernández, J.; Trujillo, Y.; Durán, D. Contenido fenólico e identificación de levaduras de importancia vínica de la uva isabella (Vitis labrusca) procedente de Villa del Rosario (Norte de Santander). Vitae 2011, 18, 17-25.

17. Scorzetti, G.; Petrescu, I.; Yarrow, D.; Fell, J. Cryptococcus adeliensis sp. nov., a xylanase producing basidiomycetous yeast from Antarctica. Antonie Van Leeuwenhoek Int. J. Gen. Mol. Microbiol. 2000, 77, 153-157, doi:10.1023/A:1002124504936.

18. Cheng, K.C.; Demirci, A.; Catchmark, J.; Puri, V. Modeling of pullulan fermentation by using a color variant strain of Aureobasidium pullulans. J. Food Eng. 2010, 98, 353-359, doi:10.1016/j.jfoodeng.2010.01.011.

19. Agarbati, A.; Canonico, L.; Ciani, M.; Comitini, F. The impact of fungicide treatments on yeast biota of Verdicchio and Montepulciano grape varieties. PLOS ONE 2019, 14, doi:10.1371/journal.pone.0217385.

20. Ocón, E.; Garijo, P.; Santamaría, P.; López, R.; Olarte, C.; Gutiérrez, A.; Sanz, S. Comparison of culture media for the recovery of airborne yeast in wineries. Lett. Appl. Microbiol. 2013, 57, 241-248, doi:10.1111/lam.12103.

21. Renouf, V.; Claisse, O.; Lonvaud-Funel, A. Understanding the microbial ecosystem on the grape berry surface through numeration and identification of yeast and bacteria. Aust. J. Grape Wine Res. 2005, 11, 316-327, doi:10.1111/j.1755-0238.2005.tb00031.x.

22. Maicas, S.; Mateo, J. Hydrolysis of terpenyl glycosides in grape juice and other fruit juices: A review. Appl. Microbiol. Biotechnol. 2005, 67, 322-335, doi:10.1007/s00253-004-1806-0.

23. López, S.; Mateo, J.; Maicas, S. Characterisation of Hanseniaspora isolates with potential aroma enhancing properties in muscat wines. S. Afr. J. Enol. Vitic. 2014, 35, 292-303.

24. Mateo, J.; Garcerà, P.; Maicas, S. Unusual non-Saccharomyces yeasts isolated from unripened grapes without antifungal treatments. Fermentation 2020, 6, 41, https://doi.org/10.3390/fermentation6020041

25. Wirth, F.; Goldani, L. Epidemiology of Rhodotorula: An emerging pathogen. Interdiscip. Perspect. Infect. Dis. 2012, 2012, doi:10.1155/2012/465717.

(C) 2020 by the authors. Licensee MDPI, Basel, Switzerland. This article is an open access article distributed under the terms and conditions of the Creative Commons Attribution (CC BY) license (http:/ / creativecommons.org/licenses/by/4.0/). 